\title{
Geranyl Favonoid from Breadfruit Regulate Dyslipidemia in Hypercholesterolemic Rat
}

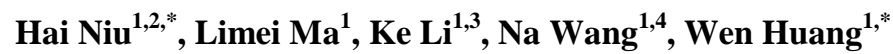 \\ ${ }^{1}$ Laboratory of Ethnopharmacology, Institute for Nanobiomedical Technology and Membrane Biology, Regenerative Medicine \\ Research Center, West China Hospital, West China Medical School, Sichuan University, Chengdu, Sichuan, China \\ ${ }^{2}$ College of Mathematics, Sichuan University, Chengdu, China \\ ${ }^{3}$ College of Light Industry, Textile and Food Engineering, Sichuan University, Chengdu, Sichuan, China \\ ${ }^{4}$ Xinhua Hospital Attached to Dalian University, Department of Plastic Surgery, Dalian, Liaoning, China \\ *Corresponding author: niuhai@scu.edu.cn; huangwen@scu.edu.cn
}

Received May 25, 2015; Revised June 27, 2015; Accepted July 09, 2015

\begin{abstract}
Hpercholesterolemia is closely related to oxidative damages from high fat and cholesterol intakes. The geranyl flavonoid (GF) from Artocarpus altilis (Breadfruit) has potential antioxidant, anti-hyperlipidemia and antiatherogenic properties. This work was to investigate the influence of GF on synthesis of cholesterol and lipogenesis in hypercholesterolemic rat fed with high-cholesterol diet. Treatment with GF significantly increased SOD, CAT, GPx and GR activities in organ tissues, as well as decreased TBARS activity compared to the untreated group. Total glutathione, NO and $\alpha$-tocopherol contents in liver, kidney and adipose tissues in GF treated group were also higher than that in untreated group. In addition, the GF treatment increased ACAT and fatty acid synthase activities, and decreased HMG-CoA reductase activity. The results suggest that treatment of GF could inhibit the synthesis of cholesterol and the lipogenesis by regulating ACAT, HMG-CoA reductase and fatty acid synthase activities and improving the antioxidant defense status in hypercholesterolemic rat.
\end{abstract}

Keywords: hypercholesterolemia, geranyl flavonoid, antioxidant enzyme

Cite This Article: Hai Niu, Limei Ma, Ke Li, Na Wang, and Wen Huang, "Geranyl Favonoid from Breadfruit Regulate Dyslipidemia in Hypercholesterolemic Rat.” Journal of Food and Nutrition Research vol. 3, no. 6 (2015): 399-404. doi: 10.12691/jfnr-3-6-7.

\section{Introduction}

The literature studies in both human and animals have demonstrated that prolonged high cholesterol concentration in the circulating blood positively correlated with developing dyslipidemia and atherosclerosis [1]. Antioxidants and hypocholesterolemic agents are known to reduce hypercholesterolemic atherosclerosis [2]. Feeding antioxidants attenuate the atherogenic process in animal models, mainly due to their free radical scavenging capabilities [3]. As plants were rich sources of natural compounds with antioxidant activities, many studies have been conducted searching for the pharmacological activities of plants and their bioactive constituents $[4,5]$.

Artocarpus altilis (breadfruit) is a species of flowering tree in the mulberry family which is rich in natural Geranyl flavonoid (GF) and has been used as food and medicines for the treatment of liver cirrhosis, hypertension, and diabetes in many centuries [6,7]. The beneficial effects for human health have been ascribed to the antioxidative, anti-hypercholesterolemic and anti-atherosclerotic properties of extract of Artocarpus altilis [8,9,10]. Therapeutic effects of food and herbal medicines rich in GF have led to a rapid growth of knowledge in this area $[8,9,10,11]$. The natural flavonoids from many plants have also been reported to have anti-inflammatory, antioxidative, anti-hypercholesterolemic and anti-atherosclerotic activities $[12,13,14,15]$. To the best of our knowledge, the effect of GF from Artocarpus altilis on hypercholesterolemia related to its antioxidative property has not been symmetrically evaluated.

The current study was conducted to determine the effect of GF on the serum lipid profile, tissues lipid peroxidation and antioxidant enzymes activities in rats fed with highcholesterol diet. We hypothesized that the unsaturated fatty acids and bioactive compounds in GF would be able to lower cholesterol levels and reduce oxidative stress in rats fed a high-cholesterol diet. In the work, we divided the rats into three groups which were treated with GF samples. The effects of consumption of GF on serum lipid profile, tissues lipid peroxidation and antioxidant enzymes activities were compared between each groups in the rats. Based on the results from our present investigation, it could be concluded that GF will be a new natural product for treating hypercholesterolemia.

\section{Materials and methods}

\subsection{Chemicals}

${ }^{14} \mathrm{C}$-acetyl-coenzyme A (CoA) was purchased from PerkinElmer (Waltham, MA, USA) and ${ }^{14} \mathrm{C}$-oleyl-CoA 
was purchased from Amersham Biosciences (St. Louis, MO, USA). All other chemicals and reagents were of the highest grade commercially available and purchased from Guoyao Chemical Reagent Co., Ltd. (Chengdu, China).

\subsection{Isolation and purification of GF}

Acorn cup of Artocarpus altilists was kindly supplied by Wuming Company, Yunxi, Guangxi, China. $1000 \mathrm{~g}$ of acorn fringe dried in air was crushed and extracted with acetone- $\mathrm{H}_{2} \mathrm{O}(7: 3, \mathrm{v} / \mathrm{v})$ for $48 \mathrm{~h}$ at room temperature on a rotative table (135 rpm). After filtration, the acetone was removed by vacuum distillation and the aqueous residue was freeze-dried $(99.6 \mathrm{~g} / \mathrm{kg})$.

The above freeze-dried extract was loaded onto a Sephardic LH20-100 column $(80 \mathrm{~cm} \times 30 \mathrm{~mm}$ i.d, 25-100 $\mathrm{mm}$ particule size) and conducted with $300 \mathrm{ml} \mathrm{H}_{2} \mathrm{O}$ (fraction 1), $300 \mathrm{ml} \mathrm{H} \mathrm{H}_{2} \mathrm{O}-\mathrm{MeOH}$ (fraction II) and $300 \mathrm{~mL}$ of $\mathrm{MeOH}$ (fraction III) for elution. Each fraction was dried on a rotary evaporator at $30{ }^{\circ} \mathrm{C}$. Regeneration of the column was achieved by successive elutions with $500 \mathrm{~mL}$ HCI (10 mM), $500 \mathrm{~mL}$ of $\mathrm{NaOH}(10 \mathrm{mM})$ and stabilized by $1 \mathrm{~L}$ of $\mathrm{H}_{2} \mathrm{O}$. Fraction II contained the main GF peaks observed by analytical HPLC [16].

These compounds were purified from fraction II by preparation TLC on cellulose (WF254, Merck, $10 \times 10 \mathrm{~cm}$ $\times 2 \mathrm{~mm}$ ) and elution with $\mathrm{H}_{2} \mathrm{O}-\mathrm{HOAc}$. Compounds were recovered from the adsorbent by elution with $\mathrm{H}_{2} \mathrm{O}$ and the aqueous filtrate was freeze-dried. The dried extract was analyzed for purity of GF by HPLC and liquid chromatography electrospray ionization mass spectroscopy (LC-ESI/MS). The purified GF were stored at $4{ }^{\circ} \mathrm{C}$ for further investigation.

\subsection{Animal Modeling, Group and Treatment}

A total of 30 male Wistar rats weighing from 200 to 250 g were purchased from Experiment Animal Academe, Medical College of Sichuan Province, China. After 1 week of acclimatization, the rats were randomly divided into three groups $(n=10)$ : Group 0 feeding on with a normal diet, Group I feeding on a normal high-cholesterol diet (consist of 47\% normal pulverized chow, 2\% cholesterol, 1\% sodium cholate, $40 \%$ dextrose, $10 \%$ lard and $15 \%$ water), Group II feeding on a high-cholesterol diet and given GF in a dose of $360 \mathrm{mg} / \mathrm{kg}$ for 20 days. After the experiment, the animals were anesthetized with sodium pentobarbital and blood was collected from abdominal aorta into dried tubes, centrifuged at $4^{\circ} \mathrm{C}$, $3000 \mathrm{~g}$ for $15 \mathrm{~min}$. Serum was taken and red blood cells were separated and then washed three times by resuspending in $0.9 \% \mathrm{NaCl}$ solution and repeated the centrifugation. The cells were lysed in an equal volume of water and mixed thoroughly. Liver, heart, kidney, and adipose tissues were also quickly excised in ice-cold saline, blotted on filter paper and weighed. All experiments were carried out according to the guidelines for the care and use of experimental animals and approved by institutional animal ethical committee.

\subsection{Determination of Serum Lipid and Hepatic Enzymes}

TC, TG, HDL-C and LDL-C in serum were determined by using enzymatic kits (Bioengineering Co., Ltd, China) according to the manufactures' instructions. ALP, AST and ALT were assayed by using the corresponding commercial kits (Bioengineering Co., Ltd, China).

Acyl-coenzyme a: cholesterol acyltransferase (ACAT) was measured in the postnuclear fraction of liver by using ${ }^{14} \mathrm{C}$-oleyl-CoA as a substrate and silica gel plates for separation of the product [18]. The activity of HMG-CoA reductase was measured in the postnuclear fraction of the liver by using ${ }^{14} \mathrm{C}-\mathrm{HMG}-\mathrm{CoA}$ as a substrate and silica gel plates for separation of the product [19]. The activity of fatty acid synthase in the liver was also measured in the postnuclear fraction as described previously [20].

\subsection{Determination of Lipid Peroxidation}

Thiobarbituric acid reactive substance (TBARS) concentrations of tissues, as a marker of the lipid peroxidation, were measured according to the method of Quintanilha et al. using tetramethoxypropane (Prolabo) as precursor of malondialdehyde [21]. Briefly, one milliliter of diluted sample (protein concentration about $2 \mathrm{mg} / \mathrm{mL}$ ) was added to $2 \mathrm{~mL}$ of thiobarbituric acid (final concentration, $0.017 \mathrm{mmol} / \mathrm{L}$ ), plus butylated hydroxytoluene (concentration, $3.36 \mathrm{mmol} / \mathrm{L}$ ) and incubated for $15 \mathrm{~min}$ at $100^{\circ} \mathrm{C}$. After cooling and centrifugation, the absorbance of supernatant was measured at $535 \mathrm{~nm}$. The TBARS levels were expressed as mmol of TBARS produced/mLof serum.

\subsection{Detection of Antioxidant Enzyme Levels in Tissues}

Superoxide dismutase (SOD) activity was measured at $412 \mathrm{~nm}$ by the NADH oxidation procedure [22] and compared with those of standard solution of SOD activity. Glutathione peroxidase (GPx) was determined by the method of Paglia and Valentine (1967 ) by using cumene hydroperoxide as substrate [23]. One unit of GPx was defined as the oxidation by $\mathrm{H}_{2} \mathrm{O}_{2}$ of $1 \mathrm{mmol} / \mathrm{L}$ of reduced glutathione per min at $\mathrm{pH} 7$ at $25^{\circ} \mathrm{C}$. Glutathione reductase (GR) activity was evaluated at $340 \mathrm{~nm}$ by measuring the decrease in NADPH absorbance in the presence of oxidized glutathione [24]. One unit of enzyme reduces 1 $\mathrm{mmol} / \mathrm{L}$ oxidized glutathione per min at $\mathrm{pH} 7$ at $25{ }^{\circ} \mathrm{C}$. Catalase activity (CAT) was determined by the method of Aebi (1974) by measuring the rate of decomposition of $\mathrm{H}_{2} \mathrm{O}_{2}$ at $240 \mathrm{~nm}$ [25]. Glutathione was measured according to the procedure of Anderson (1985) by using reduced glutathione as standard [26].

\subsection{Detection of Nitric Oxide and Vitamin in Tissues}

Nitric oxide determination was performed by using the Griess reagent (sulphanilamide and n-naphtylethylene diamine) [27]. Serum and tissue extracts were clarified by zinc sulphate solution and $\mathrm{NO}_{3}$ was then reduced to $\mathrm{NO}_{2}$ by shaking with cadmium at $20^{\circ} \mathrm{C}$ overnight. Samples were added to the Griess reagent and incubated for $20 \mathrm{~min}$ at room temperature. The absorbance was measured at 540 nm. Sodium nitrite was used for a standard curve. Serum retinol and $\alpha$-tocopherol were analyzed by highperformance liquid chromatography with an Angilent system (1100HPLC, USA) after hexane extraction. Tocol (Sigma) was added to samples as an internal standard [28]. 


\subsection{Statistical Analysis}

All values are expressed as mean \pm S.D. The significance of differences between the means of the treated and untreated groups have been calculated by unpaired Student's $t$-test and $P$-values less than 0.05 were considered significant.

\section{Results}

\subsection{Effect of GF on Serum Lipid Profile}

As shown in Table 1, the rats in Group I have extremely high lipid levels and develop serious liver damage in response to a high-cholesterol diet compared to the rats in Group 0 feeding on a normal diet, which is identical to that in humans system. The serum TC, TG and LDL-C levels decreased in Group II treated with GF by 36.3\%, $43.5 \%$ and $45.8 \%$, respectively, whereas the level of serum HDL-C increased by $17.1 \%$ as compared to untreated group $(P<0.05)$. In addition, animals fed with high-cholesterol diet in Group I exhibited an elevation in serum ALP, AST and ALT levels compared to the Group II, administration of GF could reduce ALP, AST and ALT activities as can be observed in Table 1 . The results demonstrated that a high-cholesterol diet contributed to the accumulation of lipids and could be used to construct a stable experimental model, therefore, we selected the Group I and Group II for the future determination.

Table 1. Effects of GF on the serum lipid level

\begin{tabular}{|c|c|c|c|}
\hline Parameter & Group 0 & Group I & Group II \\
\hline TC $(\mathrm{mg} / \mathrm{dL})$ & $77.4 \pm 8.9$ & $136.8 \pm 10.0$ & $86.1 \pm 4.3^{*}$ \\
\hline TG $(\mathrm{mg} / \mathrm{dL})$ & $58.2 \pm 7.2$ & $125.3 \pm 9.3$ & $70.7 \pm 3.7^{*}$ \\
\hline LDL $(\mathrm{mg} / \mathrm{dL})$ & $15.2 \pm 10.0$ & $59.3 \pm 4.3$ & $30.6 \pm 4.6^{*}$ \\
\hline HDL(mg/dL) & $24.5 \pm 1.9$ & $22.2 \pm 1.1$ & $25.7 \pm 1.6$ \\
\hline ALT (IU/L) & $21.2 \pm 3.0$ & $36.3 \pm 3.5$ & $22.3 \pm 2.2^{*}$ \\
\hline AST (IU/L) & $22.7 \pm 1.9$ & $40.2 \pm 3.9$ & $23.3 \pm 2.5^{*}$ \\
\hline ALP (IU/L) & $299 \pm 24.5$ & $512.7 \pm 45.8$ & $306 \pm 27^{*}$ \\
\hline
\end{tabular}

Values are mean \pm S.D of 10 parallel measurements. $* P<0.05$, compared with Group I. Group I, high-cholesterol diet-fed rats; Group II, high-cholesterol diet plus GF-fed rats.

\subsection{Effect of GF on Lipid Peroxidation in Tissues}

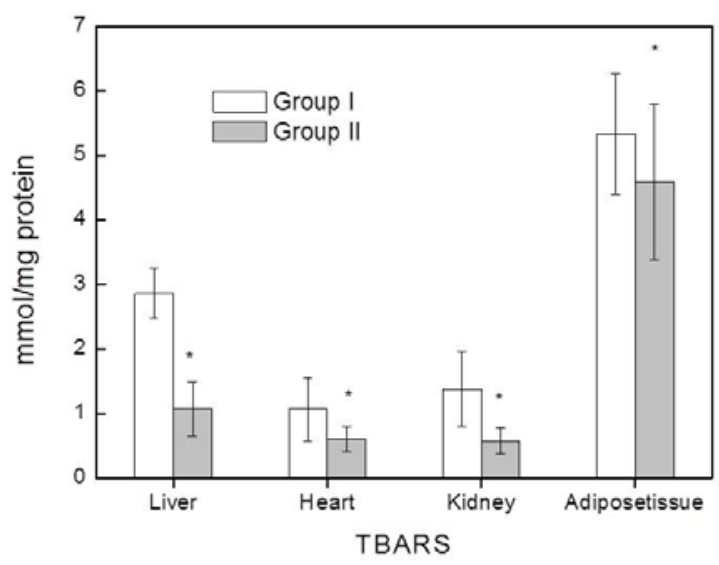

Figure 1. Thiobarbituric acid reactive substances (TBARS) contents in tissues (mmol/mg protein). Values are mean \pm S.D of 10 parallel measurements. * $P<0.05$, compared with Group I. Group I, highcholesterol diet-fed rats; Group II, high-cholesterol diet and GF-fed rats
Oxygen free radical and lipid peroxidation are vitally important in body's metabolism process. Oxygen free radicals contributes to the reaction of unsaturated fatty acid lipid peroxidation and leads to the happening of tissue damage. As shown in Figure 1, the GF treatment could decrease the lipid peroxidation in liver, heart, kidney and adipose tissues, especially in liver, compared with the untreated group, suggesting that GF could protect against lipid peroxidation and have the potential to be used for the treatment of anti-oxidation.
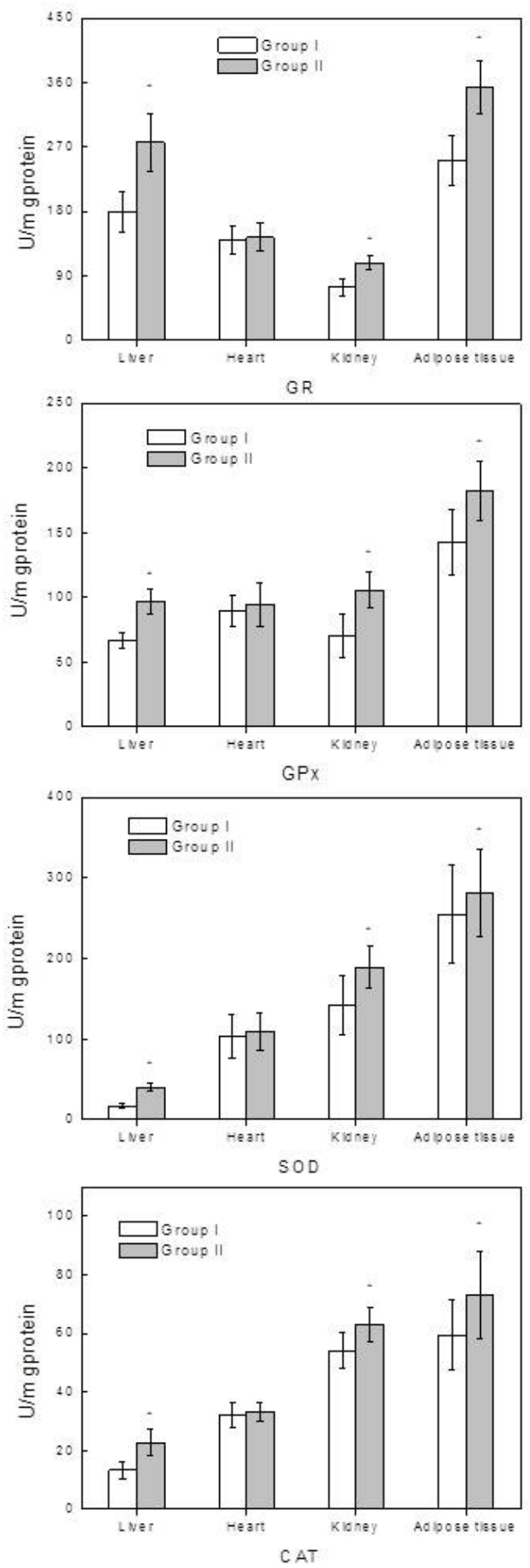

Figure 2. Antioxidant enzyme activity in tissues. A, glutathione reductase (GR); B, glutathione peroxidase (GPx); C, superoxide dismutase (SOD); D, catalase (CAT) Values are mean \pm S.D of 10 parallel measurements. * $P<0.05$, compared with Group I. Group I, high-cholesterol diet-fed rats; Group II, high-cholesterol diet and GF-fed rats 


\subsection{Effect of GF on Antioxidant Enzyme Activities in Tissues}

As presented in Figure 2, the GF treatment could significantly increase the activities of glutathione reductase (Figure 2A), glutathione peroxidase (Figure 2B), superoxide dismutase (Figure 2C) and catalase (Figure 2D) in liver, kidney and adipose tissues compared to the untreated groups $(P<0.05)$, while the activities of those enzyme were similar in liver in both GF treated and untreated groups $(P>0.05)$.

\subsection{Effect of GF on Glutathione in Tissues}

The total glutathione content in hearts was similar in rats treated with or without GF, while it was higher in liver, kidney and adipose tissues in the GF treated group as compared to that untreated group $(P<0.05)$, especially in liver, suggesting that GF could enhance antioxidation function and protect against oxidative damage caused by oxygen radicals such as ROS and SOD in rat feed on a high-cholesterol diet (Figure 3).

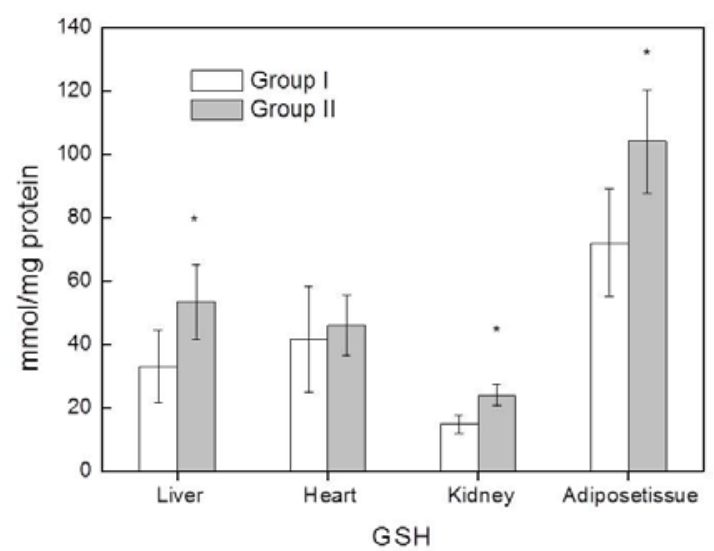

Figure 3. Total glutathion content (GSH) in tissues (mmol/mg protein). Values are mean \pm S.D of of 10 parallel measurements. ${ }^{*} P<0.05$, compared with Group I. Group I, high-cholesterol diet-fed rats; Group II, high-cholesterol diet and GF-fed rats

\subsection{Effect of GF on Glutathione in Nitric Oxide Levels and Vitamin Contents}

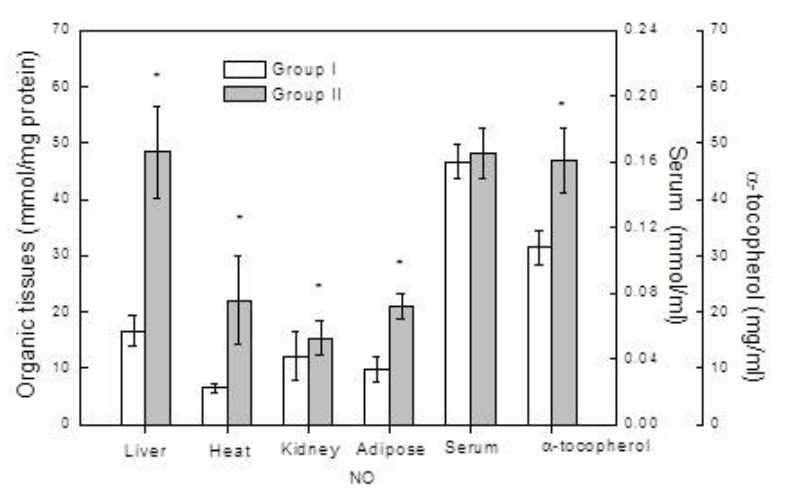

Figure 4. Nitric oxide (NO) levels in serum $(\mathrm{mmol} / \mathrm{mL})$ and tissues (mmol/mg protein) and vitamins contents in serum $(\mathrm{mg} / \mathrm{mL})$. Values are mean \pm S.D of 10 parallel measurements. ${ }^{*} P<0.05$, compared with Group I. Group I, high-cholesterol diet-fed rats; Group II, highcholesterol diet and GF-fed rats

It is clear that the content of Nitric oxide (NO) in serum was similar between GF treated and untreated groups $(P>$
0.05), however, it was higher in liver, heart, kidney and adipose tissues in the GF treated group than the untreated group $(P<0.05)$. It can be also noted that the $\mathrm{GF}$ treatment could significantly enhance the content of $\alpha$ tocopherol (Figure 4).

\subsection{Effect of GF on Activities of ACAT, HMG-CoA Reductase and Fatty Acid Synthase in Liver}

Both hepatic ACAT (catalyzing the esterification of cholesterol) and fatty acid synthase in the GF treated group increased significantly compared with the untreated group ( $P<0.05$ ), while HMG-CoA reductase (the ratelimiting enzyme of cholesterol synthesis) in the GF treated group appeared to be reduced (Table 2). These results demonstrated that GF could active the ACAT, HMG-CoA reductase and fatty acid synthase in liver and stimulate the catabolism of lipids induced by high-cholesterol diet.

Table 2. Activities of HMG CoA reductase and fatty acid synthase in liver

\begin{tabular}{|c|c|c|c|}
\hline Groups & ACAT & $\begin{array}{c}\text { HMG-CoA } \\
\text { reductase } \\
\text { (U/mg protein) }\end{array}$ & $\begin{array}{c}\text { Fatty acid } \\
\text { synthase } \\
\text { (U/mg protein) }\end{array}$ \\
\hline Group I & $0.04 \pm 0.009$ & $4.12 \pm 0.35$ & $4.43 \pm 0.51$ \\
\hline Group II & $0.07 \pm 0.006$ & $3.20 \pm 0.22^{*}$ & $5.28 \pm 0.47^{*}$ \\
\hline
\end{tabular}

Values are mean \pm S.D of 10 parallel measurements. $* P<0.05$, compared with Group I. Group I, high-cholesterol diet-fed rats; Group II, high-cholesterol diet and GF-fed rats.

\section{Discussion}

Hypercholesterolemia is an important risk factor in the initiation and progression of atherosclerotic lesions [1]. Most studies have proved that hypercholesterolemia is closely related to the deleterious effects of high dietary fat intake on lipoprotein such as an increase of serum LDL, TC, TG levels and a decrease of HDL level [29]. Epidemiological evidence from many studies overwhelmingly supports the fact that the presence of antioxidant is significantly associated with a reduction in the level of lipoprotein [30]. In our study, administration of GF from Artocarpus altilists to rats fed on a highcholesterol diet significantly reduce these abnormal lipoprotein and liver function indices, indicating that GF has a strong anti-hypercholesterolemia effect and protect against the liver damage induced by high-cholesterol diet.

ACAT plays a critical role in production of cholesteryl ,which catalyzes the formation of cholesteryl esters from cholesterol and long-chain fatty acyl-CoAs, thereby eliminating the potential toxic effects of excess cholesterol in cells [31]. Availability of its substrates may be involved in regulating the activity of ACAT, and the cholesteryl esters produced by ACAT may be secreted as part of LDL or stored in the cytoplasm. Our results showed that the increasing of ACAT and fatty acid synthase activities as well as the decreasing HMG-CoA reductase activity could lead to a decrease in the synthesis of cholesterol lipogenesis in GF treated rats.

Studies have shown that hypercholesterolemia was accompanied by an increasing of lipid peroxidation in clinical examination and experiments. It has been established that phenolic substances exert as an 
antioxidant which can prevent the development of hypercholesterolemia as well as atherosclerosis [2]. Our work showed that GF could significantly lower TBARS concentrations in all tissues such as liver, heart, kidney and adipose tissues, a marker of lipid peroxidation, suggesting that GF could be a good source against the deterioration of atherosclerosis and the accumulation of cholesterol. In addition, numerous evidence have confirmed that dietary cholesterol (2\%) consumption by rats could increase lipid peroxidation, as measured by enhanced TBARS concentrations, which was attributed to hypercholesterolemia and hypertriglyceridemia induced by high dietary cholesterol consumption [32]. Our study demonstrated that rats fed GF are less susceptible to peroxidative damage under the challenge of oxidative stress such as a high cholesterol diet.

It is well known that an increasing production of superoxide anion in hypercholesterolemic vessels mainly contributes to the dyslipidemia and atherosclerotic process [33]. It is also been reported that hypercholesterolemic atherosclerosis was associated with an increasing content of lipid peroxidation products in tissues. [8]. In this work, we investigated the SOD activity in liver, kidney and adipose tissues treated with GF, and found that the rats administration to GF exhibited higher SOD activity compared to the untreated group. A number of evidence have confirmed that free radicals in the human body is a crucial etiological factor contributing to the lipid peroxidation which leads to several chronic diseases, SOD is the first line of defense against the oxidative damage. Our work suggested that GF could prevent and treat oxidative stress and hypercholesterolemia induced by free radicals and lipid peroxidation mainly owing to the absence of accumulation of superoxide anion radicals, which was consistent with the previous reports [15].

Glutathione (GSH) is a tripeptide of glutamate, cysteine and glycine which is found in most mammalian and many prokaryotic cells. GSH participates as a coenzyme and is involved in protecting many cells with high intracellular GSH levels against oxidative damage caused by oxygen radicals such as ROS and SOD. Glutathione peroxidase (GSH-Px), which catalyses the reduction of peroxides, protects cells from the deleterious effects of peroxides [7]. In the present investigation, higher GPx and GR activities in liver, kidney and adipose tissues were observed in GF treated rats compared to those untreated rats, indicating that GF could regulate the balance between GPx and GR activities and enhance the activity of glutathione oxidation/reduction cycle. Since the elevated GSH-Px activities might enhance the utilization of GSH levels (a substrate for GPx), the intracellular GSH levels may be the major mechanism for regulation of GPx activity [34,35]. Indeed, studies have demonstrated that feeding a high-cholesterol diet in rat could decrease glutathione peroxidase activity in the liver [15]. The results in our study showed that GF could increase the SOD, GR, GPx and CAT activities in liver, kidney and adipose tissues in rats induced by an high-cholesterol diet, which was agreement with the previous report [15].

Onody et al. [36] reported that NO level was significantly decreased in rats feeding on a highcholesterol diet, and found that the decreasing of NO level is secondary event to the increasing of superoxide and peroxinitrite formation. In this work, higher NO level in liver, heart, kidney and adipose tissues was observed in rats treated with GF, which probably due to the enhanced process of $\mathrm{NO}$ biosynthesis or the weaken of $\mathrm{NO}$ elimination process. In addition, we also found that the SOD activity was higher in GF treated group than untreated group, suggesting that the increasing of $\mathrm{NO}$ content might be the consequence of decreased formation of SOD.

In conclusion, our results showed that the GF from Artocarpus altilists could significantly inhibit the dyslipidemia and decrease LDL-C, TC and TG levels and increase HDL-C level by improving the antioxidant status as well as enhancing the antioxidant enzymes activities induced by free radicals and lipid peroxidation. The results suggest the potential utility of GF as a natural source of antioxidant and anti-cholesterol against hyperlipidemia, atherosclerosis, obesity, or other cardiovascular diseases. The further studies are required to investigate the molecular mechanism of antioxidative and hypercholesterolemic effect of GF from Artocarpus altilists.

\section{Acknowledgement}

Financial supports of this research were from the China National “11.5” Foundation (No. 2006BAB04A14) and Sichuan province foundation (No. 2008SZ0024). All animal experiments were conducted according to the Institutional Animal Care and Use Committee Guidelines.

\section{References}

[1] Kim, E. H., Lee, J. B., Jo, M. W., Kim, E. H., Kim, S. H., Hwang, J. Y., Bae, S. J., Jung, C. H., Lee, W. J., Park, J. Y., Park, G. M., Kim, Y. H., Kim, H. K., Choe, J., "Serum Triglyceride Levels and Cardiovascular Disease Events in Koreans”. Cardiology 131. 228235. 2015.

[2] Sengupta, A., Ghosh, M., "Reduction of cardiac and aortic cholesterol in hypercholesterolemic rats fed esters of phytosterol and omega-3 fatty acids”. Journal of Food Science and Technology 52. 2741-2750. 2015.

[3] Scalbert, A., Johnson, I. T., Saltmarsh, M., "Polyphenols: Antioxidants and beyond". American Journal of Clinical Nutrition 81. 215-217. 2005.

[4] Zhu, Y. Z., Huang, S. H., Tan, B. K. H., Sun, J., Whiteman, M., Zhu, Y. C., "Antioxidants in Chinese herbal medicines: a biochemical perspective”. Natural Product Reports 21. 478-489. 2004.

[5] Singh, R. P., Dhanalakshmi, S., Agarwal, R., "Phytochemicals as cell cycle modulators”. Cell Cycle 1. 156-161. 2002.

[6] Mahmoud, A. M., Soliman, A. S., "Rutin attenuates hyperlipidemia and cardiac oxidative stress in diabetic rats”. Journal of Medical Science 34. 287-302. 2013.

[7] Liu, Y., Ragone, D., Murch, S. J., "Breadfruit (Artocarpus altilis): A source of high-quality protein for food security and novel food products”. Amino Acids 47. 847-56. 2015.

[8] Jalal, T.K., Ahmed, I. A., Mikail, M., Momand, L., Draman, S., Isa, M. L., Abdull Rasad, M. S., Nor Omar, M., Ibrahim, M., Abdul Wahab, R., "Evaluation of antioxidant, total phenol and flavonoid content and antimicrobial activities of Artocarpus altilis (breadfruit) of underutilized tropical fruit extracts”. Appl Biochem Biotechnol 175. 3231-3243. 2015.

[9] Adaramoye, O. A., Akanni, O. O., "Effects of Methanol Extract of Breadfruit (Artocarpus altilis) on Atherogenic Indices and Redox Status of Cellular System of Hypercholesterolemic Male Rats”. Advances in Pharmacological Sciences 2014. 605425. 2014.

[10] Wang, Y., Deng, T., Lin, L., Pan, Y., Zheng, X., "Bioassay-guided isolation of antiatherosclerotic phytochemicals from Artocarpus altilis”. Phytotherapy Research 20. 1052-1055. 2006. 
[11] Liu, Y., Ragone, D., Murch, S. J., "Breadfruit (Artocarpus altilis): a source of high-quality protein for food security and novel food products”. Amino Acids. 2015.

[12] He, X.Q., Wang, Li. P., Grazyna, S., Bi, Y. Y., Ma, Q., "Resveratrol Inhibits Paraquat-Induced Oxidative Stress and Fibrogenic Response by Activating the Nuclear Factor Erythroid 2-Related Factor 2 Pathway". Journal of Pharmacology and Experimental Therapeutics 5342. 81-90. 2012.

[13] Kardum, N., Takić, M., Šavikin, K., Zec, M., Zdunić, G., Zdunićb, G., "Effects of polyphenol rich chokeberry juice on cellular antioxidant enzymes and membrane lipid status in healthy women”. Journal of Functional Foods 9. 89-97. 2014.

[14] Zhong, K., Li, X. J., Gou, A. N., Huang, Y. N., Bu, Q., \& Gao, H., "Antioxidant and Cytoprotective Activities of Flavonoid Glycosides-rich Extract from the Leaves of Zanthoxylum bungeanum". Journal of Food and Nutrition Research 2. 349-356. 2014.

[15] Ma, L. M., Li, K., Wei, D. D., Xiao, H. Y., Niu, H., Huang, W., "High Anti-oxidative and Lipid-lowering Activities of Flavonoid Glycosides-rich Extract from the Leaves of Zanthoxylum bungeanum in Multi-system”. Journal of Food and Nutrition Research 3. 62-68. 2015.

[16] Sengupta, A., Ghosh, M., "Reduction of cardiac and aortic cholesterol in hypercholesterolemic rats fed esters of phytosterol and omega-3 fatty acids". Journal of Food Science and Technology 52. 2741-2750. 2015.

[17] Pirjo, M., Heikki, S., Lasse, L., Juhani, K., Terttu, V., “Analysis of oak tannins by liquid chromatography-electrospray ionisation mass spectrometry.” Journal of Chromatography 891. 75-83.2000.

[18] Field, F. J., Albright, E. S., "Inhibition of acylcoenzyme A: cholesterol acyltransferase activity by PD128042: effect on cholesterol metabolism and secretion in CaCo-2 cells”. Lipids 26. 1-8. 1991.

[19] Brown, M. S., Goldstein, J. L., "Dietschy JM. Active and inactive forms of 3-hydroxy-3-methylglutaryl coenzyme A reductase in the liver of the rat. Comparison with the rate of cholesterol synthesis in different physiological states.” Journal of Biological Chemistry 254. 5144-5149. 1979.

[20] Roncari, D. A., "Fatty acid synthase from human liver.” Methods in Enzymology 71. 73-79. 1981.

[21] Quintanilha, A.T., Packer, L., Davies, J.M., Racanelli, T.L., Devies, K.J., "Membrane effects of vitamin E deficiency: bioenegetic and surface charge density studies of skeletal muscle and liver mitochondria." Annals of The New York Academy of Sciences 393. 32-47. 1982.

[22] Elstner, E.F., Youngman, R.J., Obwald, W., "Superoxide dismutase In Berg Meyer, H. (Ed.), Verlag Chemie, Weinheim, Germany”. Methods of Enzymatic Analysis. 293-302. 1983.
[23] Paglia, D.E., Valentine, W.N., "Studies on the quantitative and qualitative characterization of erythrocyte glutathione peroxidase". Clinical Chemistry and Laboratory Medicine 70. 158-169. 1967.

[24] Goldberg, S., Goldberg, D.M., Spooner, R.J., “Glutathione reductase In Berg Meyer, H. (Ed.), Verlag Chemie, Weinheim, Germany”. Methods of Enzymatic Analysis. 258-265. 1992.

[25] Aebi, H., "Catalase. In: BergMeyer, H. (Ed.), Verlag Chemie, Weinheim, Germany”. Methods of Enzymatic Analysis. 673-684. 1974.

[26] Anderson, M.E., "Determination of glutathione and glutathione disulfide in biological samples". Methods Enzymol 113. 546-555. 1985.

[27] Cortas, N., Wakid, N., Determination of inorganic nitrate in serum and urine by a kinetic cadmium-reduction method. Clinical Chemistry 36. 1440-1443. 1990.

[28] Sameera, A., Talegawkar, E. J., Johnson, T. C., Carithers, H. A., Taylor, Jr., Margaret, L., Bogle, K. L., Tucker., "Serum carotenoid and tocopherol concentrations vary by dietary pattern among african americans”. Journal of the American Dietetic Association 108. 2013-2020. 2008.

[29] Sung, K. C., Reaven, G., "Fasting plasma triglyceride concentration: A possible approach to identify increased risk of statin-induced type 2 diabetes”. Diabetes \& Vascular Disease Research. 2015.

[30] Nicole, S., Ursula, S., August, H., "Rosuvastatin protects against oxidative stress and DNA damage in vitro via upregulation of glutathione synthesis”. Atherosclerosis 199. 278-287. 2008.

[31] Chang, T. Y., Chang, C. C., Cheng, D., “Acyl-coenzyme A: cholesterol acyl-transferase”. Annual Review of Biochemistry 66. 613-638. 1997.

[32] Ishiyama, A., Atarashi, K., Minami, M., Tagaki, M., Kimura, K., Goto, A.,Omata, M., "Role of free-radicals in the pathogenesis of lipid-induced glomerulosclerosis in rats”. Kidney International 55. 1348-1358. 1999.

[33] Ohara, Y., Peterson, T. E., Harrison, D. G., "Hypercholesterolemia increases endothelial superoxide anion production”. Journal of Clinical Investigation 91. 2546-2551. 1993.

[34] Stadman, T. C., "Selenium dependent enzymes". Annual Review of Biochemistry 49. 403-406. 1980.

[35] Dimitris, T., Ioannis, A., Charalambos, A., "Role of inflammation and oxidative stress in endothelial progenitor cell function and mobilization: Therapeutic implications for cardiovascular diseases”. Atherosclerosis 201. 236-247. 2008.

[36] Onody, A., Csonka, C., Giricz, Z., Ferdinandy, P., "Hyperlipidemia induced by a cholesterol-rich diet leads to enhanced peroxynitrite formation in rat hearts”. Cardiovascular Research 58. 663-670. 2003. 